\title{
Review Article \\ Effects of Heliox in Stable COPD Patients at Rest and during Exercise
}

\author{
Matteo Pecchiari \\ Dipartimento di Fisiopatologia e dei Trapianti, Università degli Studi di Milano, Via Mangiagalli 32, \\ 20133 Milano, Italy
}

Correspondence should be addressed to Matteo Pecchiari, matteo.pecchiari@unimi.it

Received 16 August 2012; Accepted 14 September 2012

Academic Editor: N. G. Koulouris

Copyright ( 92012 Matteo Pecchiari. This is an open access article distributed under the Creative Commons Attribution License, which permits unrestricted use, distribution, and reproduction in any medium, provided the original work is properly cited.

Heliox has been administered to stable chronic obstructive pulmonary disease (COPD) patients at rest and during exercise on the assumption that this low density mixture would have reduced work of breathing, dynamic hyperinflation, and, consequently, dyspnea sensation. Contrary to these expectations, beneficial effects of heliox in these patients at rest have been reported only sporadically, and the majority of the studies performed until now suggests that heliox is not a therapeutic option in spontaneously breathing resting COPD patients. On the other hand, when it is administered to COPD patients exercising at a constant work rate, heliox systematically decreases dyspnea sensation, and, often but not always, increases exercise tolerance. For these reasons, heliox has been evaluated as a non pharmacological tool to power rehabilitation programs. The conflicting results provided by the published trials probably point at a substantial heterogeneity of the COPD patients population in terms of respiratory mechanics and gas exchange. Therefore, further studies, aimed to the identification of mechanisms conditioning the response of exercising COPD patients to heliox, are warranted, before heliox administration, which is costly and cumbersome, can be routinely used in rehabilitation programs.

\section{Introduction}

The clinical use of helium-oxygen mixtures (heliox) in patients with asthma or with larynx or trachea obstruction was first described in 1934 by Barach [1]. From then, the interest in the clinical use of heliox declined, in part because of the discovery of bronchodilators and in part because of the loss of many locations of natural helium during the Second World War [2]. The enthusiasm for heliox resurged in the late 1980s, concomitantly with increased mortality from asthma [3]. At present, the use of heliox has been advocated for a number of conditions, like upper airway obstruction, croup, acute asthma, and postextubation stridor [4]. Heliox has been administered in chronic obstructive pulmonary disease (COPD) patients on the assumption that this gas mixture, because of its low density, is able to reduce pulmonary resistance. It is thus worth to briefly revise the physical properties of heliox and their impact on the dynamics of the respiratory system.

\section{Physical Properties of Helium}

Helium is the lighter element after hydrogen and it heads the noble gas series in the periodic table, with an atomic number of 2 and an atomic weight of $4 \mathrm{~g} \mathrm{~mol}^{-1}$. Due to its low melting and boiling point, at ambient temperature and pressure it exists as a gas. Helium is considerably less dense and slightly more viscous than air: dry, at $37^{\circ} \mathrm{C}$ and $1 \mathrm{~atm}$, its density is $0.157 \mathrm{Kg} \mathrm{m}^{-3}$ and its viscosity $204 \mu \mathrm{P}$ (for comparison, in the same conditions air density and viscosity are $1.134 \mathrm{Kg} \mathrm{m}^{-3}$ and $190 \mu \mathrm{P}$, resp.). The solubility coefficient of helium in water is very low compared to nitrogen, oxygen, and carbon dioxide (at $37^{\circ} \mathrm{C} 0.0014,0.014,0.03$ and $1 \mathrm{~g} / \mathrm{L}$, resp.).

Because of its low solubility, helium passes the alveolarcapillary membrane very slowly, despite its diffusibility is greater than that of oxygen, carbon dioxide, and even nitrogen. The single orbital of helium is completely filled by two electrons, so helium does not form compounds. It is regarded as metabolically inert and appears as a colourless, 
odourless, and tasteless gas. Unlike xenon, it is devoid of anesthetic properties. As a therapeutic gas, helium is used to replace nitrogen as a carrier gas for oxygen. The percentage of oxygen in heliox (which will be indicated from now on as subscript) should be at least $20 \%$ to prevent hypoxia, and no more than $40 \%$, because beyond this value heliox is not likely to exert any relevant clinical effect [5]. The density of a helium-oxygen mixture can be obtained as the weighted mean of oxygen and helium densities [6]. At $37^{\circ} \mathrm{C}$ and $760 \mathrm{mmHg}, 20 \%, 30 \%$, and $40 \% \mathrm{O}_{2}$ in He have densities of $0.377,0.488$, and $0.600 \mathrm{Kg} \mathrm{m}^{-3}$, respectively. In contrast, the viscosity of heliox mixtures cannot be obtained as the weighted mean of oxygen and helium viscosities, because the viscosity of a gas mixture is higher than the average viscosity of individual gases. By using the semiempirical formula of Wilke [7], at $37^{\circ} \mathrm{C}$ and $760 \mathrm{mmHg}$, the viscosities of $20 \%, 30 \%$, and $40 \% \mathrm{O}_{2}$ in He result 225,226 , and $226 \mu \mathrm{P}$, respectively.

From a technical point of view, it is worth to note that because of the different viscosity of air and heliox, Fleish type flowmeters should be calibrated with each gas mixture. At $20^{\circ} \mathrm{C}$, the ratio between the viscosities of water vapour saturated heliox 21 and air is $\sim 1.15$, so, if the flowmeter is not recalibrated before use with heliox ${ }_{21}$, flow will be overestimated by $\sim 15 \%$. Moreover, a considerable error can be introduced if the flowmeter is calibrated using dry heliox 21 without previous humidification, because the viscosity of the dry mixture is greater than that of the water saturated mixture. In this case, expiratory flow will be underestimated by $\sim 8 \%[8]$.

\section{Fluid Dynamics}

Consider a tube of diameter $D$ in which a fluid of density $\rho$ and viscosity $\eta$ flow steadily. The regime of the flow inside the tube (laminar, transitional, or turbulent) depends on a dimensionless quantity called Reynolds number (Re), which is the ratio of inertial to viscous forces as

$$
\operatorname{Re}=\frac{\rho D v}{\eta}=\frac{4}{\pi} \frac{\rho \dot{V}}{\eta D},
$$

where $v$ is the velocity and $\dot{V}$ is the flow. Indicatively, flow is laminar if $\operatorname{Re}$ is less than $\sim 2300$, overtly turbulent if $\operatorname{Re}$ is more than $\sim 4000$, and transitional if Re is between $\sim 2300$ and $\sim 4000$. The pressure difference required to generate a given flow is greater if the flow regime is turbulent than if it is laminar, because in the former condition (a) the boundary layer is thinner and the shear near the wall is increased, and (b) the fluid elements experience accelerations which are dissipated as heat. Using the description of the conductive airways provided by Weibel [9] to calculate Re for each generation at a given flow, it can be predicted that, at rest, transitional or turbulent flow is confined to the trachea, because only in this location Re is greater than 2300 . When ventilation is increased as during exercise, Re increases in each generation and turbulence extends distally in the central airways.

Predicting the flow regime in the tracheobronchial tree on the basis of the Reynolds number actually overestimates the amount of laminar flow present, because the establishment of Poiseuille flow is not immediate at the entrance of each airway generation. Assuming a flat velocity profile of airflow at the entrance of an airway, a fully established laminar flow can be found only after a certain length from the entrance $\left(L_{e}\right)$ given by

$$
L_{e}=k_{2} \frac{\rho D v}{\eta} D=k_{2} \operatorname{Re} D
$$

where $k_{2}$ is a constant depending on Re. For Re less than 2300 and greater than $50, k_{2}$ is $\sim 0.03$; for Re less than 50, the ratio $L_{e} / D$ is constant and $\sim 1.5$. As $L_{e}$ so calculated is greater than the anatomical length of the large conducting airways, the part of the tracheobronchial tree in which flow is turbulent or transitional should be substantially greater than that estimated solely by the computed Re.

Because the kinematic viscosity of heliox ${ }_{21}$ is $\sim 4$ times that of air, substitution of air with heliox 21 causes a 4 times decrease of Re in each airway generation, possibly causing the transition of turbulent to laminar flow at some locations. Moreover, by reducing $L_{e}$, heliox can further reduce the extension of the part of the tracheobronchial tree involved by turbulence.

The ability of heliox to keep the airflow laminar is not the sole reason of its favourable effects on respiratory mechanics. Actually, heliox is able to decrease airway resistance even if the flow regime remains turbulent.

Independently of the flow regime, the relation between the flow $(\dot{V})$ and the pressure difference between the inlet and the outlet of a circular tube $(\Delta P)$ is given by

$$
\dot{V}=\pi \sqrt{\frac{1}{8} \frac{\Delta P}{L} \frac{D^{5}}{\rho f}},
$$

where $f$ is the friction factor [6]. The relation between $f$ and Re is graphically represented in the Moody's diagram.

For fully established laminar flows, $f=64 / \mathrm{Re}$. In this case (3) becomes the well-known Poiseuille's equation as follows

$$
\dot{\mathrm{V}}=\frac{\pi}{128 \mathrm{~L} \eta} \Delta \mathrm{PD}^{4}
$$

In the region of transition between laminar and turbulent flow, $f$ depends on both wall roughness and Re. For a fully established turbulent flow, if the wall of the tube is rough, $f$ is independent on the Reynolds number and dependent only on wall roughness; if the wall is smooth, $f$ is proportional to $\operatorname{Re}^{-1 / 4}$.

As $\rho$ appears in the denominator of (3) and $f$ is proportional to $\rho^{-1}$ only when laminar flow is present, the replacement of air with heliox should decrease the pressure difference necessary to generate a given flow, even if the flow regime remains overtly turbulent. Therefore, if the flow is transitional or overtly turbulent, density dependence is always present at some variable degree, according to the flow regime and to the characteristics of the airways. If the airflow is purely laminar, no benefit of heliox should be expected; conversely, airway resistance should increase, because of the increased viscosity of heliox relative to air. 


\section{Density-Dependence of Maximal Expiratory Flow in Normal Subjects and COPD Patients}

Beside reducing the pressure difference between the alveoli and the mouth which should be developed in order to generate a given flow and, consequently, the metabolic cost of breathing, heliox is potentially able to increase the maximal ventilation available to a subject. This effect is highly desirable in COPD subject, in whom ventilation can be a constraint of physical performance. In contrast, most normal subjects do not use the maximal flows available even at peak exercise [10].

The density-dependence of the maximal flows can occur only if certain conditions are met. During forced expirations, dynamic compression of the intrathoracic airways takes place, and flows become effort-independent when the pulmonary volume is less than $80 \%$ of the vital capacity. In this volume range, expiratory flow limitation occurs.

Flow limitation may result from two mechanisms: (a) the coupling between airways compliance and convective acceleration of gas (wave-speed theory) [11], or (b) the coupling between airways compliance and viscous pressure losses [12]. In case (a), the maximal flows are inversely proportional to the square root of the gas density, as the wave-speed theory states that the maximal flow $\left(\dot{V}_{\max }\right)$ inside a compliant tube is that at which the local velocity of the fluid is equal to the propagation velocity of a small disturbance travelling on the wall of the tube, according to the following equation:

$$
\dot{V}_{\max }=A \sqrt{\frac{A}{\rho} \frac{d P_{\mathrm{tm}}}{d A}},
$$

where $A\left(d P_{\mathrm{tm}} / d A\right)$ is the elastic module of the tube and $A$ the cross section.

Conversely, in case (b) the maximal flows are densityindependent, as the viscous pressure losses are determined solely by the viscosity and by the geometrical characteristics of the airways, as long as the flow-regime remains laminar.

When a normal subject forcedly expires, as long as lung volume stays in the upper two-thirds of his vital capacity, the choke point, that is, the part of the airways where dynamic compression actually limits expiratory flow, is found in the central airways, where the cross-sectional area is small, and the lateral pressure drop is largely due to convective acceleration. In this volume range, flow limitation is due to the wave-speed mechanism, and if air is replaced by heliox, maximal flows increase. In the lower third of the vital capacity, the choke point moves upstream in the peripheral airways, where the cross-sectional area is large, the flow is laminar, and the viscous mechanism is predominate. In this case the maximal flows become density-independent.

During the evolution of the disease, COPD patients experience a progressive reduction of their maximal expiratory flows that may become so low that flow-limitation is present even at rest. It is believed that the disease first arises in the peripheral airways, which are the major site of increased resistance in many COPD patients [13-15]. In line with this assumption, when air is replaced by heliox 21 the increase of maximal expiratory flow at $50 \%$ of VC $\left(\dot{V}_{\max , 50 \% \mathrm{VC}}\right)$ is generally lower in smokers than in nonsmokers [16]. However, contrary to the expectations, in COPD patients a reduced density-dependence is not a rule. In a sample of 22 COPD patients, density-dependence, defined as an increase of $\dot{V}_{\max , 50 \% \mathrm{VC}}$ greater than $20 \%$ when air is replaced by heliox 21 , was present in 11 patients [17]. In this study, patients with decreased density-dependence differed from those with normal density-dependence because of smaller vital capacity, large ratio of residual volume to total lung capacity, higher resistance, and lower static lung recoil at total lung capacity. These results suggest that different patterns of airways lesions are present in the COPD population. Even if the disease starts peripherally, central airways can be affected with variable degree, so that their mechanical properties change in a way that during maximal expiration the choke point moves in some patients to the peripheral airways, and in some others remains in the central airways.

\section{Heliox Breathing at Rest in COPD Patients}

In healthy human subjects at rest, the end-expiratory volume corresponds to the relaxation volume of the respiratory system. In COPD patients, pulmonary hyperinflation, that is, an increase of functional residual capacity above the predicted normal value, is often present, because of reduced lung recoil, as in emphysema, and/or because of dynamic hyperinflation. The latter occurs when the duration of expiration is not sufficient to allow the respiratory system to deflate to its relaxation volume prior to the next expiration, possibly because the time-constant of the respiratory system has increased (increased airway resistance) or the respiratory rate is too high. In COPD patients, dynamic hyperinflation is mainly due to the presence of tidal expiratory flowlimitation, that is, the inability to increase expiratory flow by further increasing the transpulmonary pressure during tidal breathing. The assessment of changes of dynamic hyperinflation is usually made by measuring the opposite changes of inspiratory capacity [18]. Dynamic hyperinflation and concomitant intrinsic positive end-expiratory pressure increase inspiratory work, impair inspiratory muscles function, and adversely affect hemodynamics [19]. All these factors, together with dynamic airways compression, may contribute to dyspnea $[20,21]$.

Currently, dynamic hyperinflation can be decreased by bronchodilators [22] or, in hypoxemic patients, by oxygen administration, which reduces ventilation. Heliox, by decreasing airway resistance and increasing maximal expiratory flows, could provide further relief to COPD patients.

Unfortunately, in resting COPD patients, airway resistance during heliox ${ }_{21}$ breathing can decrease [23], or remain substantially unchanged [24]. In contrast, heliox 21 has been regularly found to decrease airways resistance in healthy subjects at rest $[25,26]$, in line with the notion that, in a normal respiratory system, the resistance of the central airways, where airflow is transitional or turbulent, accounts for a substantial part of total airway resistance [27]. 
Conflicting results have been obtained also regarding the effects of heliox 21 administration on dynamic hyperinflation in COPD patients at rest. Grapè et al. [23] reported no effect of heliox ${ }_{21}$ on dynamic hyperinflation; conversely, a significant fall of end-expiratory lung volume was detected by Swidwa et al. in 15 patients [28]. It should be noted that some of these patients were studied after hospital discharge for bronchitic exacerbations or coronary artery disease, and most had a forced expired volume in one second $\left(\mathrm{FEV}_{1}\right)$ response to the bronchodilator greater than $20 \%$, an unusual finding in COPD patients. Afterwards, a lack of effect of heliox $_{21}$ on dynamic hyperinflation in COPD patients at rest has been repeatedly reported [29-34]. Recently, one study by Chiappa et al. [35] documented an average 17\% increase of inspiratory capacity at rest when air was replaced by heliox ${ }_{21}$. Their 12 COPD patients showed a marked density-dependence of maximal expiratory flows, as heliox 21 increased peak expiratory flow by $31 \%$ and forced expiratory flow between 25 and $75 \%$ of the forced vital capacity by $46 \%$.

The effects of heliox 21 on tidal expiratory flow-limitation and dynamic hyperinflation have been assessed by Pecchiari et al. and compared to those of a bronchodilator in 22 stable COPD patients at rest [29]. In all the patients who were flowlimited, heliox 21 did not decrease dynamic hyperinflation, independent of posture. In 9 out of 13 patients who were flow-limited in the sitting posture, and in all 18 patients flow limited in the supine position, the tidal expiratory $\dot{V}-V$ loops on air and heliox 21 were essentially superimposed, indicating that the choke point was located in the peripheral airways. In 4 flow-limited patients in the sitting position, heliox 21 actually abolished flow-limitation, pointing at a central localization of the choke point. In these patients, flow-limitation actually involved the last fraction of the tidal volume $\left(V_{T}\right)$, so that no increase of inspiratory capacity was detected during heliox 21 breathing. All the flow-limited patients remained flow-limited after salbutamol administration, nevertheless dynamic hyperinflation decreased as documented by the increase of inspiratory capacity, in line with what was previously reported [22]. As ventilation did not change after bronchodilator, the increase of inspiratory capacity was entirely due to higher maximal expiratory flows in the $V_{T}$ range. In the non flow-limited patients at rest, neither heliox 21 nor salbutamol caused inspiratory capacity to increase, simply because in these patients little or no dynamic hyperinflation is present at rest [36].

\section{Heliox Breathing during Exercise in COPD Patients}

COPD patients are limited in their daily activity because of exercise intolerance due to dyspnea and/or leg fatigue. As the disease worsens, physical activities are progressively reduced, causing further deconditioning and worsening quality of life. Rehabilitation can potentially interrupt this vicious cycle. To be effective, rehabilitation should be performed at a sufficiently high level of exercise, and heliox has been regarded as a promising non pharmacological tool to improve exercise tolerance of COPD patients during rehabilitation programs.
A number of different experimental approaches have been used to assess the effects of heliox ${ }_{21}$ breathing in exercising COPD patients, namely, (a) incremental work rate test on a cycle ergometer [37-40] or on a treadmill $[41,42]$, (b) constant work rate test on a cycle ergometer [30$35,37,43,44]$, and (c) endurance shuttle walking test [45].

In COPD patients cycling at increasing work rates, heliox $_{21}$ increased maximal work rate in one study only [39] out of six [37-42], and ventilation at peak exercise in three studies [38-40] out of five [37-41]. At peak exercise, dyspnea $[39,40]$ and leg discomfort sensations [39] were not affected by heliox 21 .

When COPD patients cycled to exhaustion at constant load, heliox 21 increased exercise tolerance in five [30, 31, 3335] out of six studies [30, 31, 33-36]. At isotime, ventilation was usually unaffected by heliox $21[30-33,43]$, being, relative to air, increased in only two studies $[35,44]$ and decreased in only one [34]. In contrast, at peak exercise, ventilation was increased during heliox ${ }_{21}$ breathing [30, 31, 34, 35] except than in two studies [33, 37]. Dyspnea sensation was constantly decreased by heliox 21 at isotime $[30-35,43$, $44]$, while leg discomfort was decreased [33-35, 43, 44] or unchanged $[30,31]$. At isotime, heliox 21 was able to decrease exercise-induced dynamic hyperinflation in five studies [30, $31,33,34,43]$ out of eight [30-35, 43, 44]. Of these eight trials, Vogiatzis et al. [44] did not observe any dynamic hyperinflation on air. In the COPD patients studied by Chiappa et al. [35], heliox 21 markedly increased inspiratory capacity at rest (from $1.85 \mathrm{~L}$ in air to $2.17 \mathrm{~L}$ in heliox 21 ). At isotime and peak exercise inspiratory capacity decreased relative to the rest value more during heliox 21 breathing $(-0.22$ and $-0.25 \mathrm{~L}$, resp.) than during air breathing $(-0.10$ and $-0.13 \mathrm{~L}$, resp.).

A negative correlation between heliox-induced changes of dyspnea and inspiratory capacity at isotime has been found by Palange et al. [30], as expected according to the strict relation between dynamic hyperinflation and dyspnea. Eves et al. found that the decrease of dynamic hyperinflation with heliox ${ }_{21}$, together with the increase of peak expiratory flow and the reduction of total work of breathing, explained $99 \%$ of the variance associated with increased endurance time [31]. Similar results concerning the relation between dynamic hyperinflation and exercise tolerance have been obtained by other studies $[34,35]$.

Heliox $_{21}$ breathing increased markedly the endurance shuttle walking distance [45], to the same extent than $28 \%$ oxygen in nitrogen. In the same study, heliox 28 provided further improvement relative to heliox ${ }_{21}$ or to $28 \%$ oxygen in nitrogen alone. The additive effects of helium and hyperoxia on exercise tolerance were later confirmed by Eves et al. [31]. In another research [46], heliox 30 improved the 6-min walking distance more than $100 \%$ oxygen. A study in which training on heliox 40 was compared with training on air was promising [47], showing that training on heliox 40 increased exercise tolerance and quality of life more than training on air. A following study, however, did not confirm these results [48].

Even if part of the contrasting results obtained can be related to differences in the experimental methodology 
$[49,50]$, most of the discrepancies probably depend on the heterogeneity of COPD patients. A potential confounding factor is the eventual presence of tidal expiratory flowlimitation [18], which has been investigated, using the negative expiratory pressure technique [51], only in one instance [32]. This study assessed, in 26 stable COPD patients, tidal expiratory flow-limitation, inspiratory capacity, breathing pattern, and dyspnea sensation during air and heliox $x_{21}$ breathing at rest and during exercise at $1 / 3$ and $2 / 3$ of the maximal work rate. On air, the patients who were flowlimited at rest remained flow-limited during exercise. In contrast, 4 and 7 of the patients who were not flow-limited at rest became flow-limited at $1 / 3$ and $2 / 3$ of maximal work rate, respectively. Dynamic hyperinflation was absent in the non flow-limited patients and developed only in the presence of flow-limitation. At rest, no difference was found between the breathing pattern of flow-limited and non flow-limited patients, while during exercise tidal volume increased more in non flow-limited patients. Heliox 21 did not abolish flow-limitation, had no systematic effect on breathing pattern, and reduced dynamic hyperinflation in only $25 \%$ of the flow-limited patients. A positive correlation was found between the increase of end-expiratory lung volume on air and the reduction of dynamic hyperinflation induced by heliox $x_{21}$. This finding suggests that the heliox $x_{21}$ responders are those patients who during exercise increase their operational lung volume enough so that the choke point moves from peripheral to more central airways, where the maximal flows are determined by the wave-speed mechanism and are density-dependent.

Dyspnea sensation was relieved by heliox 21 in both flowlimited and non flow-limited patients, regardless of the presence or the absence of dynamic hyperinflation. In this connection, it should be underlined that dyspnea is not necessarily related to dynamic hyperinflation, in fact, in normal subjects, dyspnea may not change with heliox ${ }_{21}$ even if dynamic hyperinflation decreases [26], and, in COPD patients, dyspnea can decrease even in the absence of dynamic hyperinflation $[32,44]$. The reduction of dyspnea documented by D'Angelo et al. [32] could thus be related to a decrease of the inspiratory work, which, depending on the extent of turbulence in the airways, can amount up to $50 \%-$ $60 \%[6,52]$.

\section{Modelling Heliox Effects on the Respiratory System}

Because of the complex behaviour of the respiratory system especially in the presence of expiratory flow-limitation and the difficulty to directly assess the relevant variables in the human subject, mathematical models of the respiratory system have been developed and used to interpret the result of experimental research. Recently, a nonlinear dynamic mathematical model of the respiratory system, including both wave-speed and viscous mechanisms determining flowlimitation, was developed by Barbini et al. [53], on the basis of Weibel symmetrical morphometric description of the tracheobronchial tree [9] and on the mechanical characteristics of airway generations reported by Lambert [54]. This model has been used to simulate the response of the respiratory system to heliox ${ }_{21}$ in the presence of different obstructive conditions, all causing tidal expiratory flow-limitation [52]: (A) moderate to marked increase of the collapsibility of the peripheral airways (i.e., airways beyond the 7th generation); (B) marked increase of the collapsibility of peripheral airways with moderate involvement of the central ones (form the 4th to 7 th generation); (C) markedly increased collapsibility of the central and peripheral airways; (D) markedly increased collapsibility of the central airways with moderate involvement of the peripheral ones. The effects of heliox 21 have been evaluated in terms of inspiratory interrupter resistance $\left(R_{\text {int }}\right)$, intrinsic positive end-expiratory pressure (PEEPi), dynamic hyperinflation and expiratory flow-limitation.

Heliox $x_{21}$ administration reduced $R_{\text {int }}$ in all cases except case $\mathrm{A}$, where the viscous pressure loss was entirely due to laminar flow. The decrease of $R_{\text {int }}$ in case $\mathrm{B}, \mathrm{C}$, and $\mathrm{D}$ was considerable, amounting to $22 \%$ in case B and $27 \%$ in case $\mathrm{C}$ and $\mathrm{D}$. Thus heliox ${ }_{21}$ should reduce the inspiratory work of breathing, accounting, at least in part, for the reduction of dyspnea sensation which has been reported in COPD patients especially during exercise [29].

In no instance heliox 21 abolished expiratory flowlimitation.

PEEPi and dynamic hyperinflation decreased with heliox $_{21}$ only trivially in case A ( $\sim$ and $\sim 7 \%$, resp.), where flow was limited by the viscous mechanism. Similar results were obtained for case B, even if the relative contribution of the viscous over the wave speed mechanism becomes relevant in the last part of the expiration only. In case $\mathrm{C}$, the decrease of PEEPi and dynamic hyperinflation was modest (22 and 23\%, resp.) because the contribution due to peripheral resistance to the total resistance of the upstream segment remained elevated. The fall of PEEPi and dynamic hyperinflation was remarkable ( 41 and $41 \%$, resp.) in case D only, where flow limitation was dominated by the wave speed mechanism and the resistance of the peripheral airways was only slightly increased.

Note that case A, B, and C can be regarded as three subsequent stages of chronic obstructive pulmonary disease, which initially involves the peripheral airways and then spreads to the whole tracheobronchial tree. Conversely, case D may represent severe asthma with mild involvement of peripheral airways or mild chronic obstructive pulmonary disease affecting mostly the central airways.

\section{Conclusions}

The administration of heliox, which is costly and cumbersome, to stable COPD patients at rest with moderate to severe disease is not warranted, because no beneficial effect in terms of breathing pattern or dynamic hyperinflation has been observed in most of the published trials. In contrast, heliox could be effective as non pharmacological tool to enhance the efficacy of rehabilitation programs, since its administration to COPD patients usually enhances their exercise tolerance, 
at least at constant work rate, and thus can be useful to increase the level of physical training. The conflicting results which have been obtained so far suggest that further research is needed in order to identify the COPD patients potentially able to benefit from this kind of rehabilitation programs.

\section{Conflict of Interests}

The author has no conflict of interests to declare.

\section{References}

[1] A. L. Barach, "Use of helium as a new therapeutic gas," Proceedings of the Society for Experimental Biology and Medicine, vol. 32, no. 3, pp. 462-464, 1934.

[2] A. D. Reuben and A. R. Harris, "Heliox for asthma in the emergency department: a review of the literature," Emergency Medicine Journal, vol. 21, no. 2, pp. 131-135, 2004.

[3] G. J. Rodrigo, C. Rodrigo, C. V. Pollack, and B. Rowe, "Use of helium-oxygen mixtures in the treatment of acute asthma: a systematic review," Chest, vol. 123, no. 3, pp. 891-896, 2003.

[4] D. L. McGee, D. A. Wald, and S. Hinchliffe, "Helium-oxygen therapy in the emergency department," Journal of Emergency Medicine, vol. 15, no. 3, pp. 291-296, 1997.

[5] D. Hess and S. Chatmongkolchart, "Techniques to avoid intubation: noninvasive positive pressure ventilation and heliox therapy," International Anesthesiology Clinics, vol. 38, no. 3, pp. 161-187, 2000.

[6] D. Papamoschou, "Theoretical validation of the respiratory benefits of helium-oxygen mixtures," Respiration Physiology, vol. 99, no. 1, pp. 183-190, 1995.

[7] C. R. Wilke, "A viscosity equation for gas mixtures," Journal of Chemical Physics, vol. 18, no. 4, pp. 517-519, 1950.

[8] N. L. Muller and N. Zamel, "Pneumotachograph calibration for inspiratory and expiratory flows during $\mathrm{HeO}_{2}$ breathing," Journal of Applied Physiology Respiratory Environmental and Exercise Physiology, vol. 51, no. 4, pp. 1038-1041, 1981.

[9] E. R. Weibel, Morphometry of the Human Lung, Springer, Berlin, Germany, 1963.

[10] E. A. Aaron, K. C. Seow, B. D. Johnson, and J. A. Dempsey, "Oxygen cost of exercise hyperpnea: implications for performance," Journal of Applied Physiology, vol. 72, no. 5, pp. 18181825, 1992.

[11] S. V. Dawson and E. A. Elliott, "Wave speed limitation on expiratory flow-a unifying concept," Journal of Applied Physiology Respiratory Environmental and Exercise Physiology, vol. 43 , no. 3, pp. 498-515, 1977.

[12] A. H. Shapiro, "Steady flow in collapsible tubes," Journal of Biomechanical Engineering, vol. 99, no. 3, pp. 126-147, 1977.

[13] J. C. Hogg, P. T. Macklem, and W. M. Thurlbeck, "Site and nature of airway obstruction in chronic obstructive lung disease," The New England Journal of Medicine, vol. 278, no. 25, pp. 1355-1360, 1968.

[14] G. W. Silvers, J. C. Maisel, and T. L. Petty, "Flow limitation during forced expiration in excised human lungs," Journal of Applied Physiology, vol. 36, no. 6, pp. 737-744, 1974.

[15] H. Van Brabandt, M. Cauberghs, and E. Verbeken, "Partitioning of pulmonary impedance in excised human and canine lungs," Journal of Applied Physiology Respiratory Environmental and Exercise Physiology, vol. 55, no. 6, pp. 1733-1742, 1983.

[16] J. Dosman, F. Bode, and J. Urbanetti, "The use of a helium oxygen mixture during maximum expiratory flow to demonstrate obstruction in small airways in smokers," Journal of Clinical Investigation, vol. 55, no. 5, pp. 1090-1099, 1975.

[17] J. A. Meados, J. R. Rodarte, and R. E. Hyatt, "Density dependence of maximal expiratory flow in chronic obstructive pulmonary disease," American Review of Respiratory Disease, vol. 121, no. 1, pp. 47-53, 1980.

[18] N. G. Koulouris, I. Dimopoulou, P. Valta, R. Finkelstein, M. G. Cosio, and J. Milic-Emili, "Detection of expiratory flow limitation during exercise in COPD patients," Journal of Applied Physiology, vol. 82, no. 3, pp. 723-731, 1997.

[19] S. B. Gottfried, "The role of PEEP in the mechanically ventilated COPD patient," in Ventilatory Failure, C. Roussos and J. J. Marini, Eds., pp. 392-418, Springer, Berlin, Germany, 1991.

[20] D. E. O’Donnell, R. Sanii, N. R. Anthonisen, and M. Younes, "Effect of dynamic airway compression on breathing pattern and respiratory sensation in severe chronic obstructive pulmonary disease," American Review of Respiratory Disease, vol. 135, no. 4, pp. 912-918, 1987.

[21] L. Eltayara, M. R. Becklake, C. A. Volta, and J. Milic-Emili, "Relationship between chronic dyspnea and expiratory flow limitation in patients with chronic obstructive pulmonary disease," American Journal of Respiratory and Critical Care Medicine, vol. 154, no. 6, pp. 1726-1734, 1996.

[22] C. Tantucci, A. Duguet, T. Similowski, M. Zelter, J. P. Derenne, and J. Milic-Emili, "Effect of salbutamol on dynamic hyperinflation in chronic obstructive pulmonary disease patients," European Respiratory Journal, vol. 12, no. 4, pp. 799-804, 1998.

[23] B. Grapè, E. Channin, and J. M. Tyler, "The effect of helium and oxygen mixtures on pulmonary resistances in emphysema," The American Review of Respiratory Disease, vol. 81, pp. 823-829, 1960.

[24] E. F. M. Wouters, F. J. Landser, A. H. Polko, and B. F. Visser, "Impedance measurement during air and helium-oxygen breathing before and after salbutamol in COPD patients," Clinical and Experimental Pharmacology and Physiology, vol. 19, no. 2, pp. 95-101, 1992.

[25] E. L. DeWeese, T. Y. Sullivan, and P. L. Yu, "Neuromuscular response to resistive unloading: helium vs. bronchodilation," Journal of Applied Physiology Respiratory Environmental and Exercise Physiology, vol. 56, no. 5, pp. 1308-1313, 1984.

[26] T. G. Babb, D. S. DeLorey, and B. L. Wyrick, "Ventilatory response to exercise in aged runners breathing $\mathrm{He}-\mathrm{O}_{2}$ or inspired $\mathrm{CO}_{2}$," Journal of Applied Physiology, vol. 94, no. 2, pp. 685-693, 2003.

[27] P. T. Macklem and J. Mead, "Resistance of central and peripheral airways measured by a retrograde catheter," Journal of Applied Physiology, vol. 22, no. 3, pp. 395-401, 1967.

[28] D. M. Swidwa, H. D. Montenegro, and M. D. Goldman, "Helium-oxygen breathing in severe chronic obstructive pulmonary disease," Chest, vol. 87, no. 6, pp. 790-795, 1985.

[29] M. Pecchiari, A. Pelucchi, E. D’Angelo, A. Forest, J. MilicEmili, and E. D'Angelo, "Effect of heliox breathing on dynamic hyperinflation in COPD patients," Chest, vol. 125, no. 6, pp. 2075-2082, 2004.

[30] P. Palange, G. Valli, P. Onorati et al., "Effect of heliox on lung dynamic hyperinflation, dyspnea, and exercise endurance capacity in COPD patients," Journal of Applied Physiology, vol. 97, no. 5, pp. 1637-1642, 2004.

[31] N. D. Eves, S. R. Petersen, M. J. Haykowsky, E. Y. Wong, and R. L. Jones, "Helium-hyperoxia, exercise, and respiratory mechanics in chronic obstructive pulmonary disease," American Journal of Respiratory and Critical Care Medicine, vol. 174, no. 7, pp. 763-771, 2006. 
[32] E. D’Angelo, P. Santus, M. F. Civitillo, S. Centanni, and M. Pecchiari, "Expiratory flow-limitation and heliox breathing in resting and exercising COPD patients," Respiratory Physiology and Neurobiology, vol. 169, no. 3, pp. 291-296, 2009.

[33] S. J. Butcher, O. Lagerquist, D. D. Marciniuk, S. R. Petersen, D. F. Collins, and R. L. Jones, "Relationship between ventilatory constraint and muscle fatigue during exercise in COPD," European Respiratory Journal, vol. 33, no. 4, pp. 763-770, 2009.

[34] P. Laveneziana, G. Valli, P. Onorati, P. Paoletti, A. M. Ferrazza, and P. Palange, "Effect of heliox on heart rate kinetics and dynamic hyperinflation during high-intensity exercise in COPD," European Journal of Applied Physiology, vol. 111, no. 2, pp. 225-234, 2011.

[35] G. R. Chiappa, F. Queiroga, E. Meda et al., "Heliox improves oxygen delivery and utilization during dynamic exercise in patients with chronic obstructive pulmonary disease," American Journal of Respiratory and Critical Care Medicine, vol. 179, no. 11, pp. 1004-1010, 2009.

[36] O. Diaz, C. Villafranca, H. Ghezzo et al., "Role of inspiratory capacity on exercise tolerance in COPD patients with and without tidal expiratory flow limitation at rest," European Respiratory Journal, vol. 16, no. 2, pp. 269-275, 2000.

[37] A. C. Raimondi, R. H. Edwards, D. M. Denison, D. G. Leaver, R. G. Spencer, and J. A. Siddorn, "Exercise tolerance breathing a low density gas mixture, 35 per cent oxygen and air in patients with chronic obstructive bronchitis," Clinical Science, vol. 39, no. 5, pp. 675-685, 1970.

[38] D. A. Oelberg, R. M. Kacmarek, P. P. Pappagianopoulos, L. C. Ginns, and D. M. Systrom, "Ventilatory and cardiovascular responses to inspired $\mathrm{He}-\mathrm{O}_{2}$ during exercise in chronic obstructive pulmonary disease," American Journal of Respiratory and Critical Care Medicine, vol. 158, no. 6, pp. 1876-1882, 1998.

[39] R. S. Richardson, J. Sheldon, D. C. Poole, S. R. Hopkins, A. L. Ries, and P. D. Wagner, "Evidence of skeletal muscle metabolic reserve during whole body exercise in patients with chronic obstructive pulmonary disease," American Journal of Respiratory and Critical Care Medicine, vol. 159, no. 3, pp. 881885, 1999.

[40] T. G. Babb, "Breathing $\mathrm{He}-\mathrm{O}_{2}$ increases ventilation but does not decrease the work of breathing during exercise," American Journal of Respiratory and Critical Care Medicine, vol. 163, no. 5, pp. 1128-1134, 2001.

[41] B. L. Bradley, J. W. Forman, and W. C. Miller, "Low-density gas breathing during exercise in chronic obstructive lung disease," Respiration, vol. 40, no. 6, pp. 311-316, 1980.

[42] J. E. Johnson, D. J. Gavin, and S. Adams-Dramiga, "Effects of training with heliox and noninvasive positive pressure ventilation on exercise ability in patients with severe COPD," Chest, vol. 122, no. 2, pp. 464-472, 2002.

[43] M. Amann, M. S. Regan, M. Kobitary et al., "Impact of pulmonary system limitations on locomotor muscle fatigue in patients with COPD," American Journal of Physiology, vol. 299, no. 1, pp. R314-R324, 2010.

[44] I. Vogiatzis, H. Habazettl, A. Aliverti et al., "Effect of helium breathing on intercostal and quadriceps muscle blood flow during exercise in COPD patients," American Journal of Physiology, vol. 300, no. 6, pp. 1549-1559, 2011.

[45] E. A. Laude, N. C. Duffy, C. Baveystock et al., "The effect of helium and oxygen on exercise performance in chronic obstructive pulmonary disease: a randomized crossover trial," American Journal of Respiratory and Critical Care Medicine, vol. 173, no. 8, pp. 865-870, 2006.
[46] D. D. Marciniuk, S. J. Butcher, J. K. Reid et al., "The effects of helium-hyperoxia on 6-min walking distance in COPD: a randomized, controlled trial," Chest, vol. 131, no. 6, pp. 16591665, 2007.

[47] N. D. Eves, L. C. Sandmeyer, E. Y. Wong et al., "Heliumhyperoxia," Chest, vol. 135, no. 3, pp. 609-618, 2009.

[48] D. Scorsone, S. Bartolini, R. Saporiti et al., "Does a low-density gas mixture or oxygen supplementation improve exercise training in COPD?" Chest, vol. 138, no. 5, pp. 1133-1139, 2010.

[49] N. C. Syabbalo, B. Krishnan, T. Zintel, and C. G. Gallagher, "Differential ventilatory control during constant work rate and incremental exercise," Respiration Physiology, vol. 97, no. 2, pp. 175-187, 1994.

[50] S. O'Connor, P. McLoughlin, C. G. Gallagher, and H. R. Harty, "Ventilatory response to incremental and constant-workload exercise in the presence of a thoracic restriction," Journal of Applied Physiology, vol. 89, no. 6, pp. 2179-2186, 2000.

[51] N. G. Koulouris, P. Valta, A. Lavoie et al., "A simple method to detect expiratory flow limitation during spontaneous breathing," European Respiratory Journal, vol. 8, no. 2, pp. 306313, 1995.

[52] C. Brighenti, P. Barbini, G. Gnudi, G. Cevenini, M. Pecchiari, and E. D'Angelo, "Helium-oxygen ventilation in the presence of expiratory flow-limitation: a model study," Respiratory Physiology and Neurobiology, vol. 157, no. 2-3, pp. 326-334, 2007.

[53] P. Barbini, C. Brighenti, G. Cevenini, and G. Gnudi, "A dynamic morphometric model of the normal lung for studying expiratory flow limitation in mechanical ventilation," Annals of Biomedical Engineering, vol. 33, no. 4, pp. 518-530, 2005.

[54] R. K. Lambert, "A new computational model for expiratory flow from nonhomogeneous human lungs," Journal of Biomechanical Engineering, vol. 111, no. 3, pp. 200-205, 1989. 




The Scientific World Journal
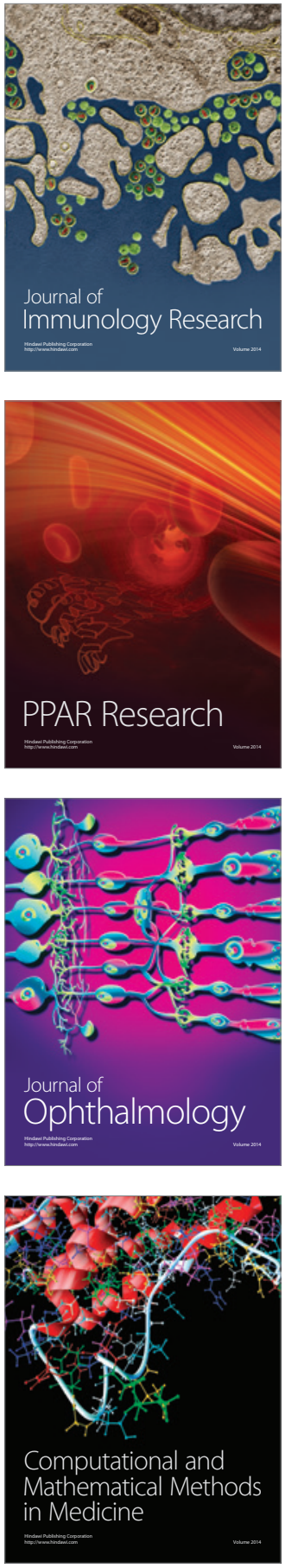

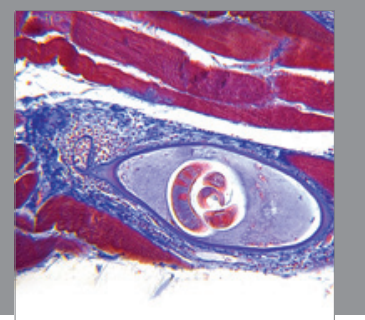

Gastroenterology

Research and Practice


\section{Hindawi}

Submit your manuscripts at

http://www.hindawi.com
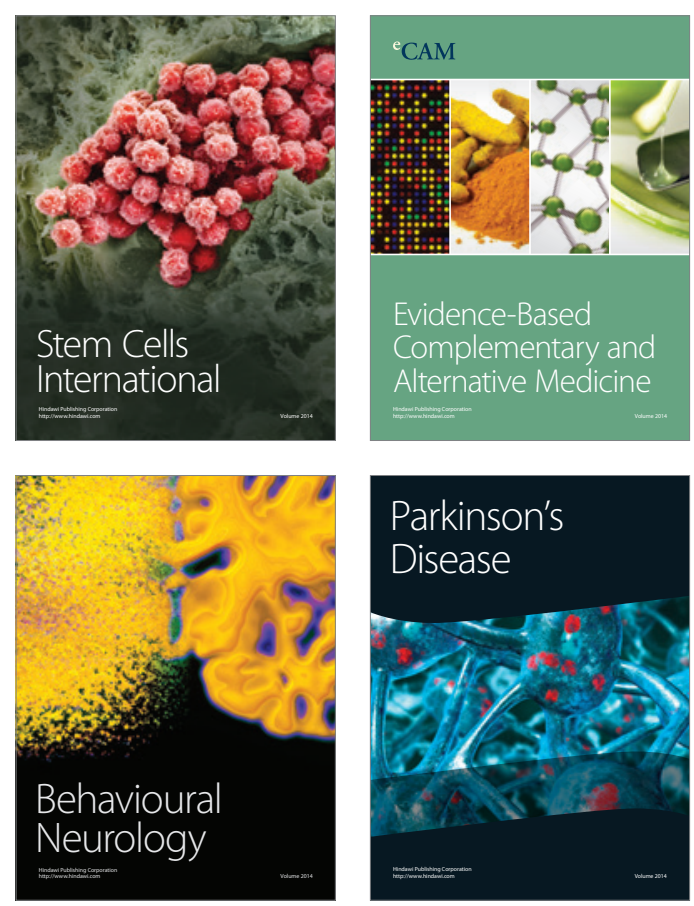



Journal of
Diabetes Research



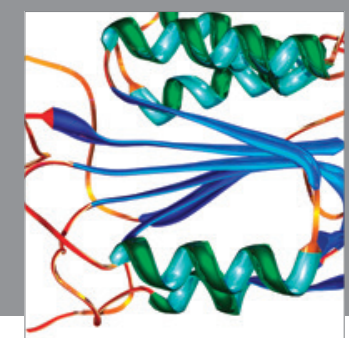

Disease Markers
